\title{
LAND USE DAN ZONASI KAWASAN CAGAR BUDAYA KOTABARU YOGYAKARTA, BERDASARKAN KONSEP GARDEN CITY
}

\author{
Yunita Kesuma ${ }^{1}$ \\ ${ }^{1}$ Program Studi S1 Teknik Arsitektur, Jurusan Teknik Sipil, Fakultas Teknik \\ Universitas Lampung, Jl. Soemantri Bojonegoro No.1, Bandar Lampung \\ Email : yunita.kesuma@gmail.com
}

\begin{abstract}
Abstrak
Kawasan Kotabaru (dulu disebut nieuwe wijk) yang merupakan usaha perluasan kota menciptakan sebuah "kota baru dalam kota" (new town in town). Pola zonasi Garden City merupakan model radial konsentris, dimana terdapat prinsip utama,yaitu: a) Civic center (taman kota pada Inti kawasan) berupa ruang terbuka di tengah kawasan yang digunakan sebagai area hijau dan dilingkupi oleh bangunan publik; b) Crystal palace (fasilitas publik di luar central park); Cincin di luar crystal palace merupakan c) kelompok rumah yang menghadap ke boulevard, d) Cincin terluar sebagai pasar, gudang, pabrik, dan fasilitas servis lainnya.

Makalah ini fokus akan melihat perubahan fungsi lanskap yang terjadi di Kota Baru Yogyakarta dari beberapa dekade. Perubahan lanskap dalam hal ini merupakan perubahan penggunaan lahan dan Zonasi kawasan Cagar Budaya, meliputi: lahan terbangun (permukiman, pertokoan, perkantoran bangunan pemerintah, fasilitas umum, dan lai-lain), lahan terbuka (taman / lapangan), lahan berair (sungai, dan kanal), dan lahan hijau (kebun dan RTH). Untuk mendapatkan dukungan data yang akurat dilakukan dokumentasi yang relevan, terkait; data tutupan lahan, interpretasi peta sejarah/Morfologi Wilayah, foto udara dan pengumpulan data statistik.
\end{abstract}

Keywords: Land Use, Zonasi, Heritage, Garden City.

\section{PENDAHUUAN}

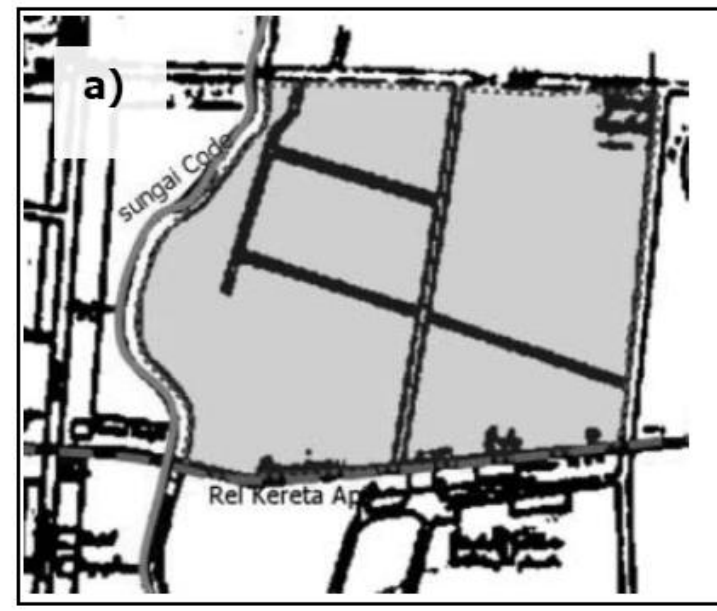

Kota Yogyakarta dalam perjalanan sejarahnya diwarnai oleh unsur pemerintahan kolonial Belanda. Menurut Darmosugito (1956;23), pemukiman Belanda pertama di Yogyakarta berada di Loji Kecil, kemudian meluas ke jalan Secodiningratan (dahulu: Kampemenstraat, sekarang jalan depan SMP 2 Yogyakarta), kemudian meluas lagi ke Bintaran dan Jetis, dan akhirnya ke Kotabaru.

Kawasan Kotabaru (dulu disebut nieuwe wijk) yang merupakan usaha perluasan kota menciptakan sebuah "kota baru dalam kota" (new town in town), khusus diperuntukkan bagi kepentingan golongan Eropa (Surjomihardjo, 1988;55) dan di dalamnya dibangun berbagai fasilitas penunjang. Kotabaru

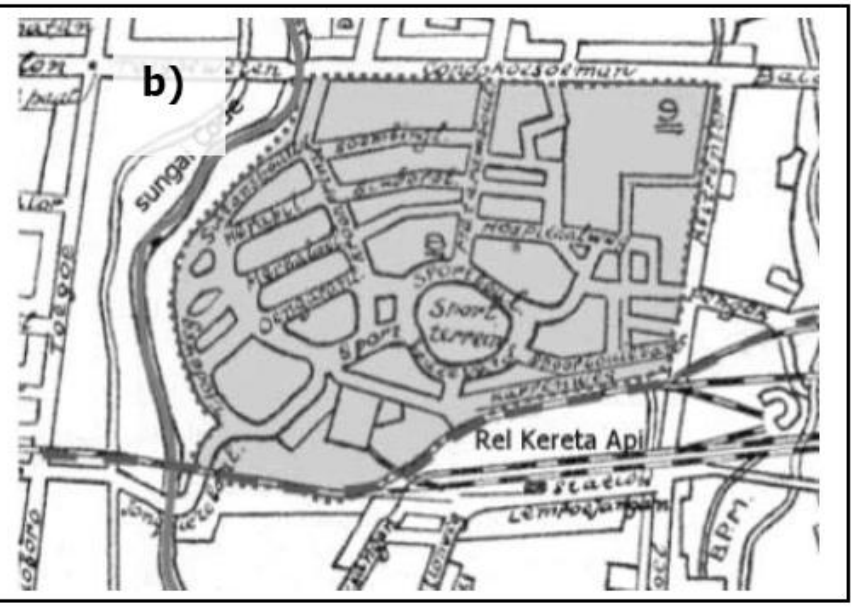

Gambar.1a Peta tahun 1903 sebelum menjadi Kotabaru, Sumber: KITVL dalam Surjomiharjo,1988;290.

Gambar 1.b Peta Kotabaru sekitar tahun 1919 Sumber: Djogdjakarta Mooi,tt.

yang merupakan kawasan permukiman kolonial berskala besar $( \pm 39 \mathrm{Ha})$ dikembangkan dengan konsep Garden City dengan kaidah-kaidah perencanaan kota modern pada awal abad ke-20 oleh Arch. En. Ing Bur. Fermont sebagai perencana kawasan, sehingga jika dibandingkan dengan kawasan cagar budaya lainnya,menjadikan kawasan Kotabaru sebagai "Kota Baru Indonesia Generasi Pertama" (Umezu, 2001;2). 


\section{ISI PENELITIAN}

\subsection{Metode Penelitian}

Metode yang digunakan dalam penelitian ini adalah metode deskriptif kualitatif. Metode pengumpulan data (primer dan sekunder) dalam penelitian ini menggunakan metode observasi (pengamatan), pengumpulan foto-foto lama, peta kawasan, peta satelit, pemotretan rekaman gambargambar frontal kondisi kawasan, penggambaran dua dimensional fasad eksisting, dan indept interview dengan beberapa narasumber. Lokasi penelitian berada di Kelurahan Kotabaru, kecamatan Gondokusuman, Kotamadya Yogyakarta. Sub lokasi amatan terpilih yaitu wilayah yang memiliki kecenderungan penataan dengan pertimbangan kaidah perancangan awal Kotabaru.

\subsection{Analisis}

Pola zonasi Garden City merupakan model radial konsentris, dimana terdapat prinsip utama,yaitu: a) Civic center (taman kota pada Inti kawasan) berupa ruang terbuka di tengah kawasan yang digunakan sebagai area hijau dan dilingkupi oleh bangunan publik; b) Crystal palace (fasilitas publik di luar central park); Cincin di luar crystal palace merupakan c) kelompok rumah yang menghadap ke boulevard, d) Cincin terluar sebagai pasar, gudang, pabrik, dan fasilitas servis lainnya.
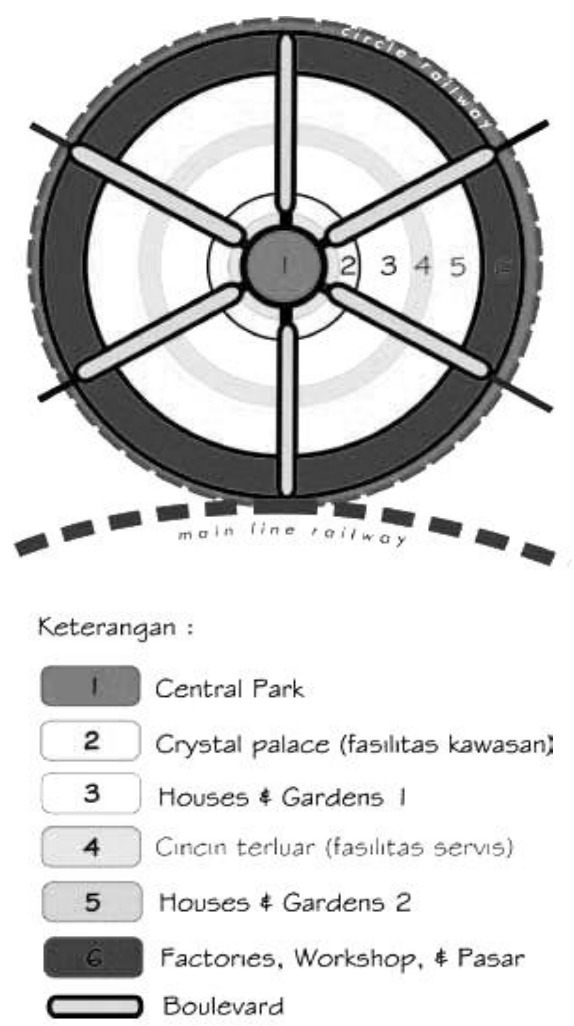

Gambar. 2

Ilustrasi prinsip zonasi garden city Sumber : Olah gambar, 2012

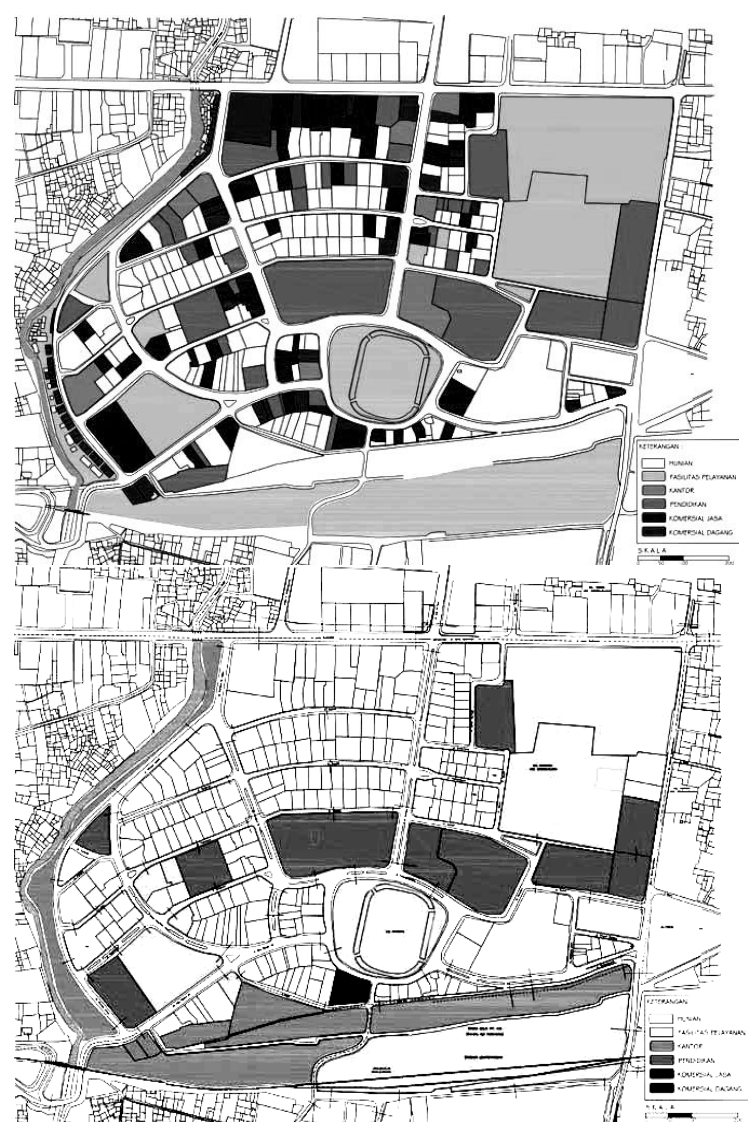

Gambar.3 Land use kawasan Kotabaru tahun 1925 Gambar.4 Land use kawasan Kotabaru Tahun 2012 Sumber : Analisis, 2012

Kawasan Kotabaru pada dasarnya masih merupakan kawasan permukiman yang di dalamnya terdapat fasilitas-fasilitas pendukung yang keberadaannya hingga saat ini secara formal belum berubah. Perubahan fungsi yang terjadi di zona permukiman yaitu fungsi residential berubah menjadi fungsi komersial jasa maupun komersial dagang. Adapun perubahan tersebut dapat dilihat pada Gambar 3 dan 4.

Penerapan zonasi/ tata guna lahan di kawasan Kotabaru tidak dipengaruhi lapisan-lapisan fungsi lahan sesuai dengan ilustrasi Howard. Peletakan fungsi komersial cenderung menempatkan fungsifungsi publik di titik-titik yang cenderung dekat dengan hunian. Prinsip kemudahan dalam menjangkau fasilitas-fasilitas publik digunakan untuk memberikan kenyamanan penduduk Kotabaru pada masanya.

Pola zonasi di kawasan Kotabaru terdapat prinsip-pinsip utama Garden City, antara lain:

\section{a. Zona Inti/ Pusat Kawasan}

Pada tahun 1925, ruang terbuka di pusat kawasan dinamakan Sport Hall Kridosono (Gambar 5.13), yang merupakan simbol kawasan yang berfungsi sebagai ruang terbuka publik, terdiri dari voetbal 
terrain (lapangan sepak bola) dan tennis terrain (lapangan tenis).
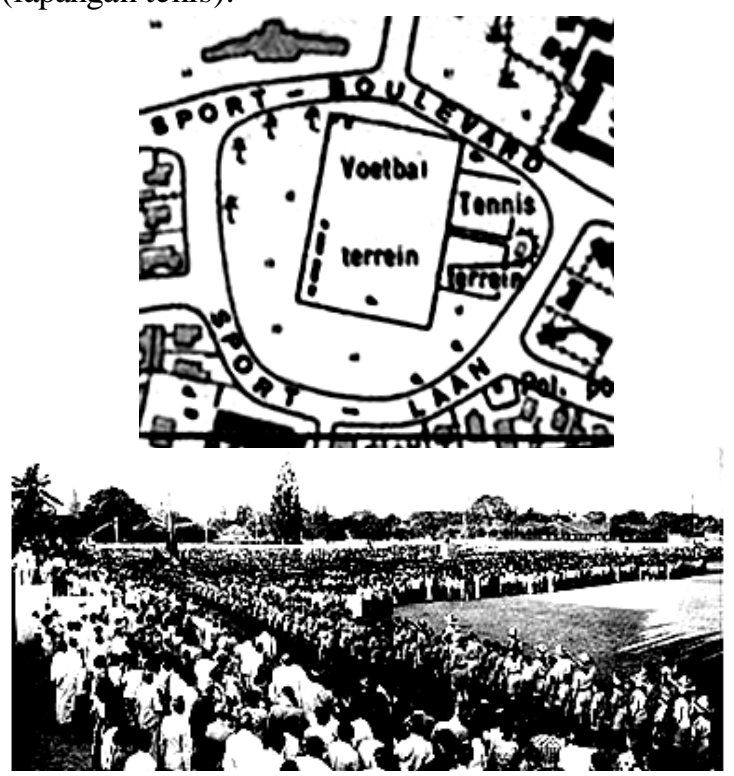

Gambar 5. Peta Sport Hall kawasan Kotabaru

Tahun 1925 (kiri) (sumber; KITLV), dan

Gambar 6 Suasana Sport Hall Tahun 1925 (kanan) (sumber; KITLV)

Berdasarkan (Gambar.5) kawasan Kridosono secara visual dapat dilihat oleh publik. Sedangkan kondisi saat ini (tahun 2012), ruang terbuka tersebut masih berfungsi sama yaitu Kridosono Sport Center. Sport hall yang semula tanpa massa bangunan, saat ini terdapat tambahan massa bangunan di bagian Barat (Gambar.6), antara lain stadion sepak bola, GOR (Indoor arena/Gedung Olahraga), dan kolam renang.
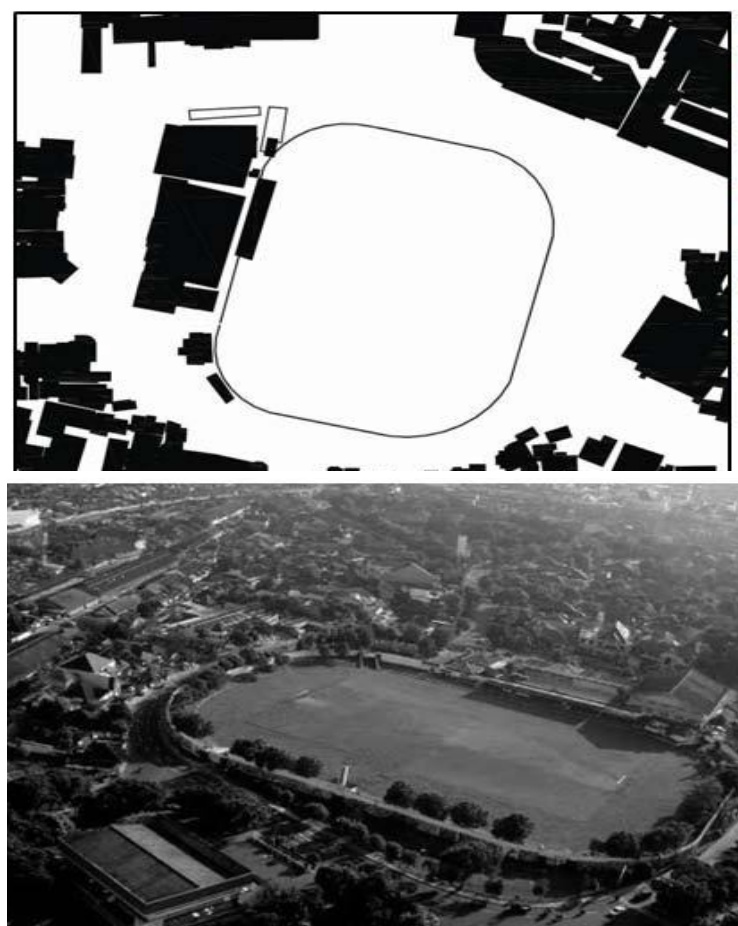

Gambar 7. Figure Ground Kridosono Tahun 2012 (atas) (sumber:Penulis,2012); \&
Gambar 8. Foto kondisi Kridosono Tahun 2012 (bawah) (sumber: panoramio.com)

Kridosono Sport Center saat ini menjadi terkesan tertutup karena dikelilingi pembatas berupa dinding massif (Gambar 5.16). Selain menjadi sarana kegiatan olahraga masyarakat Yogyakarta, Kridosono Sport Center juga digunakan sebagai ruang konser musik dan taman kuliner.

b. Zona Sarana Fasilitas Pendukung

Keberadaan fasilitas publik digambarkan dalam lapisan kedua diagram konsep garden city. Pada tahun 1925, zona fasilitas publik cenderung dikelompokkan di bagian Timur kawasan Kotabaru. Berdasarkan peta Tahun 1925, diidentifikasi berupa keberadaan beberapa fasilitas pendidikan, fasilitas kesehatan, dan keamanan, seperti:

Fasilitas Pendidikan:

1) Gouverenement Europesche Lagere School (Government European Lower-Grade School di Oengaran Weg), saat ini masih berfungsi sebagai SDN Ungaran 1, 2, 3;

2) Algemeene Middlebare School (SMU Jurusan Teknik untuk Bumiputera), saat ini bernama SMA Negeri 3 Yogyakarta;

3) Normaal School voor inlandche onderwijzeressen (sekolah untuk guru pribumi), saat ini bernama SMP Negeri 5 Yogyakarta;

4) Christelijk M.U.L.O/Meer Uitgebreid Lagere Onderwijs (SMP untuk bumiputera), saat ini berfungsi SMU BOPKRI I;

5) Kweekschool voor Inlandche Christelijke onderwijzers dan Keuchenius School (sekolah untuk mendidik anak pribumi yang kelak akan menjadi guru di sekolah Kristen), bangunan asli sudah diganti gedung Universitas Kristen Duta Wacana;

6) Land Jong School (Sekolah Dasar Kristen bagi anak pribumi), saat ini difungsikan sebagai Sekolah Tinggi Theologi Duta Wacana.

Fasilitas Kesehatan:

1) Petronella Ziekenhuis Hospital, saat ini masih berfungsi sebagai fasilitas keehatan hanya berganti nama Rumah Sakit Bethesda; dan

2) DAT Hospitaal/Militair Hospitaal, saat ini masih berfungsi sebagai fasilitas keehatan hanya berganti nama Rumah Sakit Tentara Dr Sutarto.

\section{Fasilitas Keamanan:}

1) Megazijnen van Oorlog (Gudang Amunisi Tentara Belanda), saat ini berubah fungsi menjadi asrama TNI Angkatan Darat; dan

2) Politie Post Huis, saat ini berubah fungsi menjadi hunian, sarana keamanan dipindah posisikan di bagian Utara kawasan Kotabaru. 

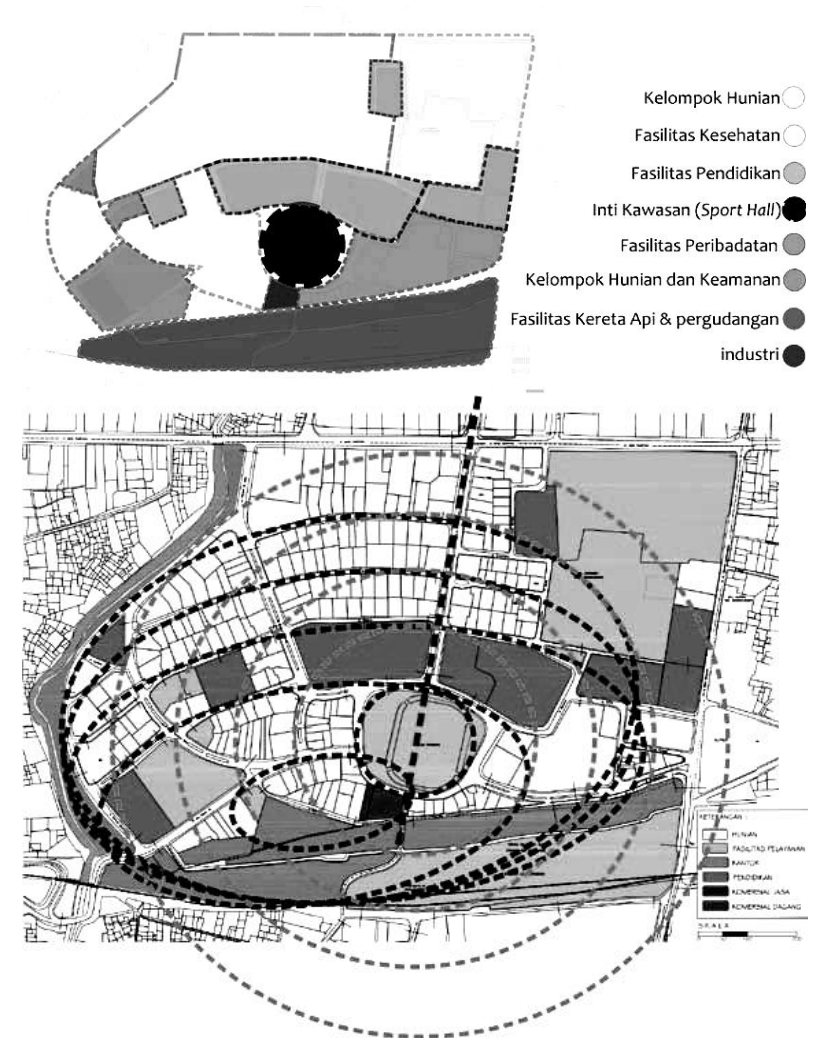

Gambar 9. Analisis Fungsi Lahan Tahun 1925 (atas) Gambar 10. Analisis Pola Zonasi Tata Guna Lahan di Kawasan Kotabaru 1925 (bawah) (sumber: Analisis, 2012)

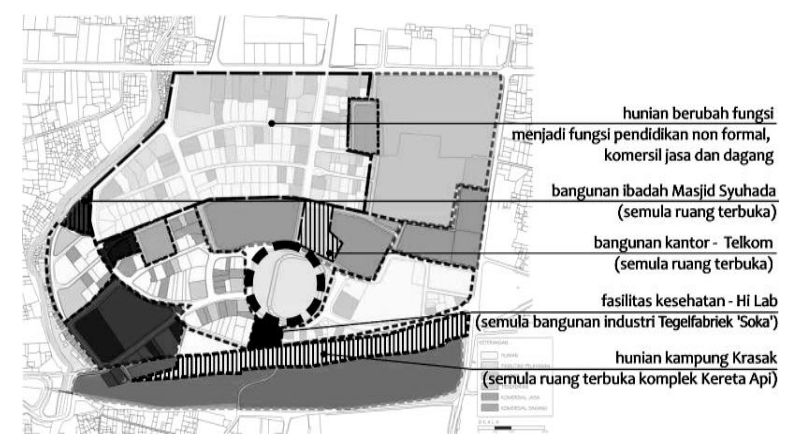

Gambar.11. Analis is Perubahan Fungsi Guna Lahan di Kawasan Kotabaru tahun 2012 (sumber:Penulis, 2012)

Berdasarkan Gambar 9, teridentifikasi fasilitasfasilitas kawasan diposisikan cenderung berada di bagian Timur, sebagian memanjang bagian Tengah, bagian Barat, dan di bagian Selatan kawasan. Fasilitas di bagian Timur berupa fasilitas kesehatan, pendidikan untuk bangsa pribumi, dan fasilitas Keamanan. Fasilitas pendidikan cenderung memanjang berada di bagian Tengah hinggacenderung ke bagian Barat, teridentifikasi berupa fasilitas pendidikan untuk Bangsa Eropa. Fasilitas kawasan bagian Barat berupa fasilitas Peribadatan. Dilihat dari pembagian zonasi tersebut, fasilitas-fasilitas tersebut cenderung berada dekat dengan hunian.

\section{c. Zona Hunian / Perumahan}

Menurut Karsten, bangunan rumah merupakan unsur penting dalam konsep kota taman, selain jalan, taman-taman dan vegetasi kota, dan bangunan publik. Zona housing and garden, diidentifikasi berupa kelompok hunian atau rumah tinggal yang menghadap ke jalan. Pembagian lingkungan perumahan di kawasan garden city, Karsten membagi lingkungan tidak berdasarkan suku, melainkan kelas ekonorni.

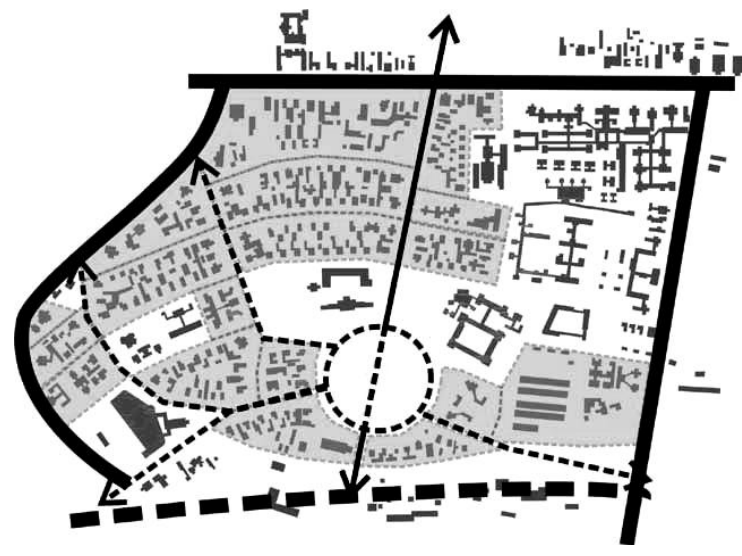

Gambar 12. Land Use Kelompok Hunian di kawasan Kotabaru Th. 1925 (sumber: Analis is, 2012)

Berdasarkan hasil penelitian Suryorini (2002;4547) pada penerapan konsep garden city di beberapa Negara Eropa, setiap unit rumah memiliki lahan yang cukup luas (sekitar 30-40\% dari luas lahan kavling) dimaksudkan agar rumah mendapat sinar matahari dan udara yang cukup. Demikian halnya dengan Karsten, sangat memperhatikan masalah kenyamanan rumah tinggal terutama pada sistem sirkulasi udara dan penerangan alaminya disesuaikan dengan iklim di Indonesia. Selain itu . Karsten menggunakan prinsip dasar Garden City yang disesuaikan dengan arsitektur dan bentuk kota di Indonesia.

\section{d. Cincin terluar (fasilitas servis)}

Hal ini ditandai dengan adanya pengelompokan fungsi publik di bagian Timur kawasan Kotabaru, diantaranya adalah:

1) Zendings Hospitaal Petronella (Rumah Sakit Petronella), saat ini masih dengan fungsi yang sama Rumah Sakit Bethesda. Dibangun tahun 1899 dan dahulu dikenal masyarakat sebagai RS Pitulungan. Pada zaman Jepang diganti namanya menjadi Yogyakarta Tjuo Bjoin, dan setelah penjajahan Jepang dikenal sebagai Rumah Sakit Pusat. Kemudian pada tanggal 28 juni 1950 diganti lagi namanya dengan Rumah Sakit Kristen "Bethesda" (sumber: www.Bethesda.or.id)

2) Tijdelijke A.M.S. (Temporary A.M.S.), berdiri sejak tahun 1899", saat ini berfungsi sebagai 
gedung Sekolah Tinggi Ilmu Kesehatan (STIKES) Bethesda Yakkum;

3) DAT Hospitaal / Militair Hospitaal. Berdiri pada tahun 1931 digunakan untuk para anggota militer. Saat ini masih berfungsi sebagai Rumah Sakit Dinas Kesehatan Tentara (RS DKT) Dr. Sutarto;

4) Sarana keamanan seperti Politie Post Huis (rumah jaga polisi), Megazijnen van Oorlog (Gudang Amunisi), dan asrama polisi. saat ini berfungsi sebagai rumah dinas (mess) Angkatan Darat.

5) Jalur Kereta Api; Stasioen Lempoejangan (Stasiun Lempuyangan), yang didirikan pada tanggal 2 Maret 1872, merupakan stasiun kereta api pertama di Yogyakarta. Jalur kereta api difungsi difungsikan khusus sebagai jalur transportasi antar kawasan yang letaknya di luar kawasan, sekaligus menjadi batas kawasan Kotabaru.

Ditinjau dari susunan zonasi, kawasan Kotabaru yang menerapkan pola radial konsentris, memiliki zona inti, zona fasilitas kawasan cenderung berkelompok namun tidak mengitari zona inti, dan zona permukiman yang berkelompok dan berada dekat dengan fasilitas-fasilitas kawasan. Hal ini menunjukkan bahwa perencanaan kawasan menempatkan zona permukiman dapat dengan mudah menjangkau fasilitas kawasan berupa fasilitas pendidikan. Kemudahan dalam menjangkau fasilitas sangat memperkuat perencanaan kawasan Kotabaru, dalam hal ini jarak tempuh antara fasilitas dan hunian disesuaikan dengan jarak tempuh pejalan kaki. Jarak tempuh berjalan kaki (jarak maksimal antara rumah tinggal dan sekolah yaitu 300500meter). Kemudahan akses dalam menjangkau fasilitas pendidikan sesuai dengan prinsip dasar Garden City dan penerapannya di beberapa kota di Negara Eropa.

\subsection{Hasil Pembahasan}

Berdasarkan pola konfigurasi solid-void kawasan, secara makro (skala Kotabaru) pola struktur kawasan mendekati model radial konsentris (Gambar 12,13, dan 14), dengan lengan-lengan radial berupa jalur jalan linier menjangkau ke luar kawasan, dari pusat kawasan dan sebaliknya. Vista yang tercipta ketika pengamat melakukan perjalanan bermuara di satu titik pusat kawasan. Susunan zonasi kawasan Kotabaru terdiri dari zona inti, zona fasilitas kawasan yang cenderung berkelompok, meskipun tidak mengitari zona inti, kelompok fasilitas-fasilitas tersebut berada dekat dengan zona permukiman. Kemudahan akses dalam menjangkau fasilitas sangat memperkuat perencanaan kawasan Kotabaru, dalam hal ini jarak tempuh antara fasilitas (khususnya fasilitas pendidikan dan peribadatan) dan hunian, disesuaikan dengan jarak tempuh pejalan kaki. Kemudahan akses dalam menjangkau fasilitas pendidikan sesuai dengan prinsip dasar Garden City dan penerapannya di beberapa kota di Negara Eropa.

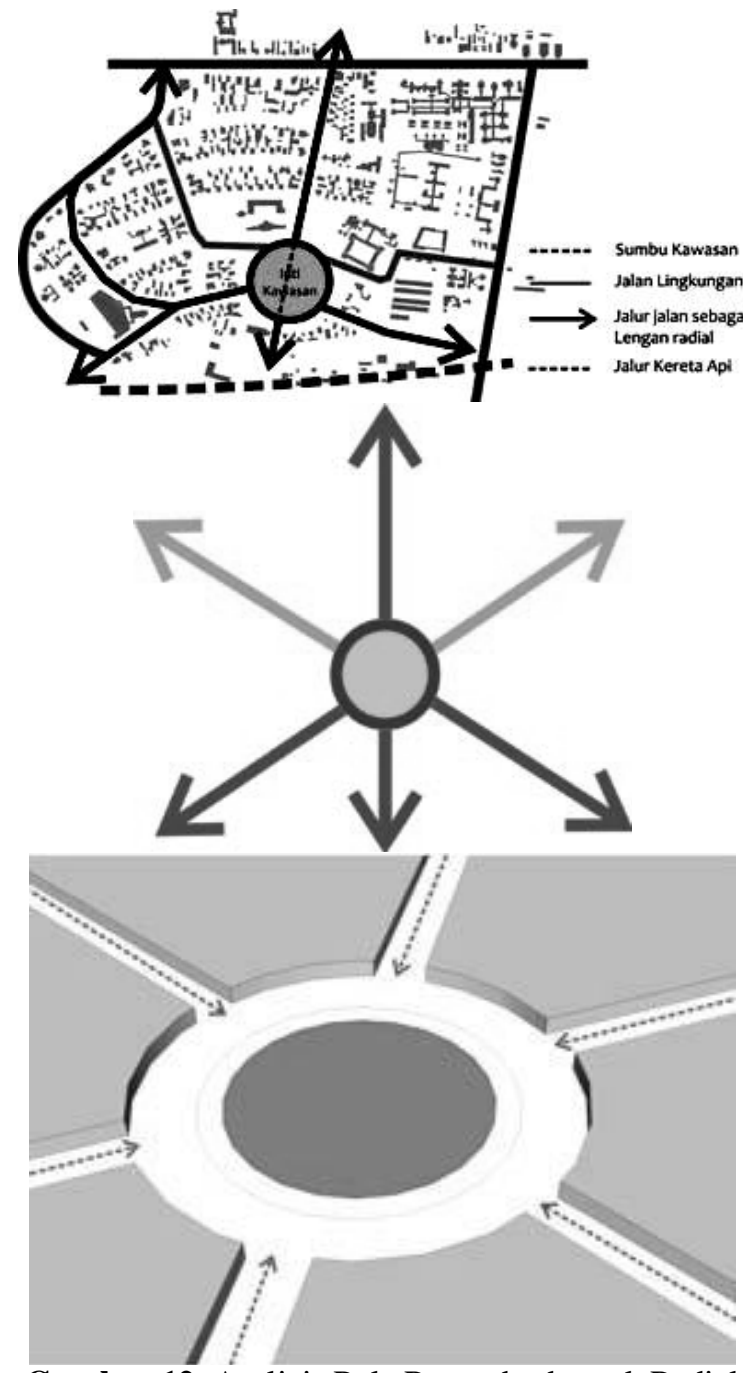

Gambar 12. Analisis Pola Ruang berbentuk Radial di Kawasan Kotabaru (sumber: analisis, 2012)

Gambar 13. Diagram pola ruang kawasan Kotabaru (sumber: analisis, 2012)

Gambar 14. Karakter Visual Yang Tercipta dari Pola Radial (sumber: Analisis Penulis, 2013)

\section{KESIMPULAN}

a. Pola ruang kawasan mendekati bentuk ring dan radial konsentris; Secara visual, pola ring (cincin) dan radial konsentris yang tercipta dari jalur-jalur jalan linier (sebagai lengan radial) di kawasan Kotabaru, masing-masing menuju satu titik pusat kawasan sehingga vista yang tercipta memperlihatkan adanya pusat kawasan berupa ruang terbuka (Kridosono Sport Hall) sebagai magnet kawasan kotabaru.

b. Kejelasan dalam pembagian zonasi permukiman; Area permukiman Kotabaru bagian Barat merupakan zona elite permukiman Belanda, berada di lingkungan strategis, dan dekat dengan fasilitas pendidikan dan peribadatan. Konsep awal 
perencanaan tersebut dimaksudkan untuk memperjelas klastering permukiman penduduk Eropa dan pribumi, termasuk penamaan jalan dengan istilah laan dan weg yang membagi dua zona elite permukiman Belanda di kawasan Kotabaru.

\section{DAFTAR PUSTAKA}

- Darmosugito, 1956, Kota Jogjakarta 200 Tahun: 7 Oktober 1756 - 7 Oktober 1956, Panitya - Peringatan Kota Jogjakarta 200 Tahun, Jogjakarta.

- Hall, Peter, 1993, Cities Of Tomorrow; An Intellectual History of Urban Planning and Design in the Twentieth Century, Blackwell, Oxford UK \& Cambridge USA.

- Mc Cluskey, Jim., 1992, Road Form and Townscape, Second Edition, Butterworth Architecture, Jordan Hill Oxford.

- Purwanto. L.M.F., Hermawan, Sanjaya. Ridwan, 2006, Pengaruh Bentuk Atap Bangunan Tradisional di Jawa Tengah Untuk Peningkatan Kenyamanan Termal Bangunan, Dimensi Teknik Arsitektur Vol. 34, No. 2, Desember 2006: 154-160, Jurnal Teknik Arsitektur Universitas Kristen Petra, Surabaya.

- Sanjaya, Cindy, 2008, Penerapan Garden City dalam Kaitannya dengan Kota Berkelanjutan, Jurnal Ilmiah Arsitektur UPH Vol.5, No.2: 99-113, Jakarta.

- Smardon, RC, 1986, Foundation for Visual Project Analysis, John Wiley and Sons Inc., New York.

- Soekiman, Djoko. 1996. Kebudayaan Indis dan Gaya Hidup Masyarakat Pendukungnya di Jawa (Abad XVII - Medio Abad XX). Yayasan Bentang Budaya. Yogyakarta.

- Surjomihardjo, Abdurrachman, 2008, Kota Yogyakarta Tempo Doeloe, Sejarah Sosial 1880-1930, Komunitas Bambu, Depok.

- Umezu, Hiroyuki Satrio, 2001, Studi Perubahan Urban Fabric Di Kawasan Pemukiman Belanda Studi Kasus Kota Baru Yogyakarta, Tesis S2 Teknik Arsitektur Universitas Gadjah Mada, Yogyakarta

- Zoraya, Olivia, 2008, Pola Pemukiman Wilayah Menteng dan Nieuw Menteng Awal Abad XX, Skripsi S1 Ilmu Pengetahuan Budaya Uni versitas Indonesia, Jakarta.

- http://www.ocw.mit.edu 